\title{
"The Story is My Life": Bridging Symbol to Self in a Novel Creative and Reflective Writing Task
}

\author{
Jacob Lang ${ }^{1,2}$, and Gerald C. Cupchik ${ }^{2}$ \\ 1 Department of Educational and Counselling Psychology, McGill University, Canada \\ 2 Department of Psychology, University of Toronto, Canada
}

\begin{abstract}
This article describes the development and testing of a novel creative and reflective writing task. Following the rationale of sand-tray and play therapies, participants were asked to meaningfully incorporate four objects from a randomly generated matrix of options into a creative short story. They then composed a second story that incorporated four possessions from home associated with important memories. Afterwards, participants produced interpretive statements or reflections on what the stories meant to them. An exploratory qualitative study was conducted based on narrative data from 15 young adult participants in Canada. Our goals were to: (a) explore the extent to which object familiarity was associated with qualitative differences in stories and interpretations, and (b) investigate for connections between features of participants' stories and depth of interpretation. Analysis of creative stories resulted in a scheme of four response categories with ten subcategories. Participants' interpretations of their own stories were coded based on self-described sources of inspiration, such as critical life episodes or popular media. Results are accompanied with excerpts of participants' stories and reflections, and percentage comparisons are reported.
\end{abstract}

\section{Article history:}

Received: September 13, 2020

Received in revised from: December 8, 2020

Accepted: April 20, 2021

\author{
Corresponding author at: \\ Jacob Lang \\ E-MAlL: jacob.lang@mail.utoronto.ca
}

Findings are presented in dialogue with established interpretive frameworks originating in depth psychology. Manipulation of object familiarity resulted in demonstrable differences at the levels of word length, point of view, narrative forms and features, self-disclosure, and reflection. Use of familiar objects in such a task appears to be a largely untapped resource that shows promise as a route to insight.

\section{KEYWORDS:}

creative writing, narrative, expression, insight, self-reflection, imagination

ISSN 2354-0036

DOI: 10.2478/ctra-2021-0014 


\section{INTRODUCTION}

This article describes the development and testing of a novel creative and reflective writing task. Following the rationale of sand-tray and play therapies, participants were asked to meaningfully incorporate four objects from a randomly generated matrix of options into a short story. They then composed a second story that incorporated four chosen possessions from home associated with important memories. Afterwards, participants were asked to reflect and compose brief interpretations of their creative products. A qualitative study was conducted based on narrative data from a sample of young adults in Canada. This exploratory study was aimed at generating hypotheses to address the following:

1. Examine the extent to which object familiarity was associated with qualitative differences in participants' stories as well as their interpretations.

2. Investigate for connections between features of participants' stories and depth of interpretation, which has implications in the psychology of insight.

\section{THEORETICAL BACKGROUND}

A personally meaningful experience is accompanied with an emotional charge, and that emotion may be reawakened alongside the memory of the meaningful episode. One of Pierre Janet's (in Ellenberger, 1981/1970) significant contributions to the development of psychotherapy was his hypothesis that les ideés fixes, obsessional thoughts resistant to conscious control (e.g. anxieties), appear to be related to painful memories. With likeness to the construct of repression, les ideés fixes may be pushed into profondeur behind defensive behavior. Janet (1920) was among the first to argue that dissolving avoidance responses to distressing memories is important to therapeutic change. An implication of psychodynamic work, broadly, is that if the subject distances from memories with negative emotional valence, they are in effect dissociating from meaning-filled episodes in their life narrative. The more avoidance persists, the more distal the subject may be from resolving la misère psychologique. Therefore, rather than avoid distressing intrapsychic stimuli - which may be termed higher resistance and lower insight in psychotherapy parlance - one may benefit from engaging with them.

A cornerstone of the insight hypothesis is the belief in an image- or story-making function (although Janet had reservations about the literary turn in psychotherapy; Bühler \& Heim, 2001). In this view, all creative works, such as story and visual artwork, like dream and fantasy, are projective devices. They may be read as expressions of the subject's mental life. Jung (1968/1964) succeeded Janet in his development of complex theory, and the relationship between the two figures is an area of renewed scholarly interest (Vezzoli, 2019). In his metapsychology, features of dreams and creative works that reflect values and patterns of engaging in relationships are categorized within the personal unconscious. Being more influenced by German Romanticism and Neo-Platonism, 
Jung's interpretive approach broadened to the collective level. He posited that imagined events and creative works are communicated in a language of archetypal themes mirroring basic human experiences. Fundamental themes include inside-outside, security-insecurity, and gain-loss (Jung, 1968/1964). Waking life, dreams, literature, and myth may be read as a trove of images of basic human experiences. From these sources emerged the classic taxonomy of archetypal images and their roles in psychic transformation or plot development (e.g., Campbell, 2008/1949). Notably, fantasy or creative content reflecting collective meanings is also argued to be inherently personal. The archetype is a potential or instinct colored by an individual's experiences of the lifeworld.

Converging with Jung, Janet assumed identity between mental wellness and the fully "integrated" personality (Ellenberger, 1981/1970). Jung posited that lower insight is associated with difficulties discerning between motivational forces leading one towards progressive/adaptive or regressive/self-sabotaging ends. Participation in psychotherapy or analysis may allow the subject to gain insight into the array of competing complexes behind behaviors. In this work, they may identify a hypothesized orienting force (anima/animus) to guide them through the deep towards existential wellbeing. Insight opens the door to a life aimed at the vanishing point of the individuating state (Jung, 1951). This hypothesis was notably informed by spiritual traditions offering routes to mystical contact. For instance, complex theory shares likeness with Ignatius Loyola's rules to the faithful for discerning the influences of holy versus evil spirits on the mind and soul (trans. 2015).

Ellenberger (1981/1970) observed that writers in classic psychoanalysis and analytical psychology described unconscious contents as entities that possess the capacity for self-determination. Complex theory would lead analysts to describe autonomous forces as sub-personalities. Each complex is like a simplistic "mind" an und für sich. It has been argued in other schools, however, that the ego may learn to engage directly with the implicit and adjust the machinery of habit (Lynn \& Rhue, 1994; Spitzer et al., 2006). Jung (1968/1964) posited that the motivational forces constituting the unconscious may only be accessible through their signifiers; symptoms and appearances in fantasy, story, dream, art, and myth. At times, it may be appropriate to dialogue with these images in active imagination to apprehend their meanings (McNiff, 2004; Shamdasani, 2009). Art therapies operate under the premise that creative activities, such as story-writing and visual arts, offer opportunities to appraise and express painful memories that may be otherwise overwhelming due to their emotional charge (Talwar, 2006). The creator has a degree of control over the distance between ego and potentially troubling unconscious contents to safely accrue insight rather than defaulting to less sophisticated defensive responses (i.e., avoidance; Slayton, D’Archer \& Kaplan, 2011).

If it is the case that creative works are projections of the inner world, then the interpretation of one's own creative works may be a means of accruing insight. This is a hypothesized mechanism behind expressive arts approaches including sand-tray therapy, which has been utilized in samples ranging from children with difficulties regulating emotions to adults in career counselling (Halpenny \& Linzmayer, 2013; Magnuson \& Sangganjanavanich, 2011). Sand-tray therapists provide clients with a set of novel objects to include in a creative display and discuss how its meanings may relate to aspects of their life narrative. The interpretive task may not only reveal sources of inspiration for 
the creative product but allow the therapist to gain a sense of the client's comfort with self-disclosure and depth of self-reflection.

Converging with constructivist thinking, it is postulated in the Zurich school that all perceived objects are coated in projections of the subject (Shamdasani, 2009). No object is "neutral." Some objects, however, may be more readily associated with personal meanings than others. Familiar objects, such as heirlooms, souvenirs, or gifts, are evocative of specific episodic memories, significant others, or aspects of the self (e.g., beliefs, hobbies and interests), whereas associations with novel objects may be less clear.

The interface between narrative identity and materiality has captured the interest of contemporary constructivist and narrative psychologists. Leary (2005) presented an autoethnographic account of the meanings of personal belongings in his life narrative. In a process analogous to archaeology, the author reflected on how four portraits of inspirational figures in his home office spoke volumes about the self:

Though I didn't plan the collection—each picture having gone up at a separate time-I see now that these four objects represent central meanings and connections in my life. Apparently even a relatively reflective academic can be too busy living his life to spend much time ruminating on the relations that hold it together. Yet I find that these relations are all around me, expressed by objects waiting to be noticed (p. 54).

Personal belongings are conduits to personal meanings. Thus, inclusion of familiar objects in a creative task, such as a written story, may load the creative product with personally significant material readily interpretable by its creator. Indeed, in grief therapy, asking the client to bring an object of connection into the consulting room, such as a photograph of the deceased, is practiced as a means of facilitating adaptive coping and honoring the continuing bond (Humphrey, 2009). Clients may also write creative stories related to the theme of loss and interpret the constituent elements (including objects, characterization, and settings; Neimeyer et al., 2011). In the latter technique, both the creative and reflective acts are understood to have therapeutic value in processing loss.

Literature on the role of object familiarity in tasks like sand-tray therapy is scant. In a research context, participants may be asked to incorporate familiar objects into a creative work and then interpret the product. A control condition would be to ask the individual to incorporate novel objects, like in conventional sand-tray and play therapies, and complete an identical interpretive task. We pilot tested a paradigm in which a single group of young adults engaged in creative story-writing and self-reflection/interpretation under these two conditions. A qualitative study was deemed the most fitting response to our aim to explore similarities and differences in participants' creative products and interpretations. Study design, implementation, and reporting of results were guided by recommendations for achieving goodness (situatedness, trustworthiness, and authenticity in qualitative research; Tobin \& Begley, 2004). Hypotheses generated from the present study will inform subsequent implementations to rigorously examine the potential role of object familiarity in facilitating self-reflection. Our research is in service of a broader goal to develop novel and effective routes to insight by means of creative activities. 


\section{METHOD}

\section{Recruitment}

In a convenience sampling procedure, English-speaking young adults were invited to participate in a study on "creative story-writing and personal meaning" from February to April 2018 through posters at a Canadian university and web advertisements in the local inter-university community. A small bonus towards a course credit for eligible students or an alternative CAD10 compensation was granted for $1.5 \mathrm{~h}$ of participation at home and at the university.

Response information was collected using Google software on a secure server. All data was treated as confidential, and participants were only identifiable by code. Primary research was conducted with approval from the Psychology Delegated Ethics Review Committee at the University of Toronto Scarborough in compliance with Canada's Tri-Council Policy Statement for Research Involving Humans.

\section{Procedures}

Preliminary tasks. Interested young adults were briefed on the procedures and provided informed consent to participate. A survey hosted by Google Forms was then sent via email asking them to: (a) Take photographs at home of four possessions that hold special, personal meaning to them, (b) send the digital images to the researchers, (c) type 1-3 sentence descriptions of their four possessions and why they chose them, and (d) provide open-ended reports of age and gender. Adequate representation of participant voices is essential to well-designed qualitative research (Tobin \& Begley, 2004). Age and gender demographics were collected so that we could contextualize the data. Participants' reported experiences related to cultural, religious, academic/professional, age, and gender identities were included in our description of the sample.

Creative story composition. Participants visited the university laboratory for the remainder of the tasks. Between one and three participants and one supervising researcher were present during data collection. Participants were seated at separate carrels for their privacy, and the researcher would relocate to an adjacent office during the writing tasks.

In the first condition, participants viewed a matrix of 36 randomly generated objects on a lab computer and selected four that they felt could easily be incorporated into a narrative. These objects were drawn from Moreno-Martínez and Montoro's (2012) colorized revision of the standard Snodgrass and Vanderwart pictorial object set. Participants were then asked to type a creative story on a theme of their choosing (approximating 500 words) in which all four chosen objects were meaningfully incorporated. The four chosen images of objects were present on the computer screen during story-writing. They were then asked to compose a second creative story in which their four objects selected at home were meaningfully incorporated. Photographs of the participant's objects sent to us via email were present on the computer screen during this task. Participants were given 20 minutes for each story. They received the same instruction in both conditions 
"to be creative, imaginative, and spontaneous in [their] writing" to elicit imagination (Chen et al., 2011; Niu \& Liu, 2009). The first story task is referred to as the novel object condition and the second as the familiar object condition in this article.

Interpretive statements. After completing both stories, they were asked to type brief, open-ended descriptions of what each story meant to them.

\section{Researcher Description}

Two researchers were involved in study design, data collection, analysis, and manuscript composition. At the time of writing, one researcher possessed graduate-level training in counselling, and the other held a doctoral degree and academic post in a psychology department. Both had familiarity with depth-oriented hermeneutics.

\section{Sample Composition}

Fifteen (15) young adults (7 males and 8 females) participated in the study. The mean age of participants in years was 18, and one participant did not disclose his age. One participant did not complete the familiar object condition story, nor the interpretive tasks. A total of 29 stories and 28 interpretive statements were included in analysis.

Regardless of the relative homogeneity of the sample (i.e., English-speaking young adults in a Canadian city), it is important to note that the study took place in a multicultural context. Diversity of identities was evident in participants' descriptions of why they chose their familiar objects. Practicing Catholic and Muslim participants addressed the significance of religion when describing why they chose prayer beads for the task. Identification with Egyptian, Irish, and Scandinavian heritage were explicitly reported. Four participants discussed gender and romantic relationships. Objects were commonly chosen to signify rites of passage, such as graduation, overcoming life-threatening illness, and degrees of achievement in martial arts. Symbolic connections to the dead, namely heirlooms and photographs, were also chosen. Birthday and Christmas gifts were common, as were objects related to hobbies and interests, including visual arts, music, athletics, and videogames.

\section{Analysis}

Objective characteristics of texts were gathered so that we could attain a clear picture of similarities and differences between conditions. Word counts of all texts were conducted. Point of view (first- or third-person narration) was also noted to gain a sense of the author's engagement or distance from the text.

Analysis of creative stories was guided by attention to narrative forms and features. First, one researcher assigned each story one code based on (a) structure, or the sequence of plot development, setting and characterization, conflicts and epiphanies, (b) thematic underpinnings of the narrative, and (c) use of figurative language with particular attention to symbol. The initial proposed coding scheme was refined in a meeting during which two researchers discussed and recoded the 
texts. This led to the development of an agreed upon taxonomy of qualitatively distinct response categories and subcategories. Reported comparisons with established interpretive approaches (e.g., Jungian theory) were made post hoc. Despite our emphasis on narrative forms and features, our analysis prioritized participants' written texts rather than contextual factors surrounding the discourse. This distances the approach from typical narrative analysis (Creswell, 2007).

Results of the analysis of short stories are reported in dialogue with findings of a thematic analysis of participants' interpretations of their stories. In an open coding process, each interpretive statement was assigned up to four codes reflecting the presence of various reported sources of inspiration for the story. This coding scheme was also refined in a consensus meeting. We anticipated diversity in the degree of sophistication across participants' reflections on the sources of their projections into their creative products. Statements of differences in the prevalence of a given code are reported as percentage comparisons.

\section{RESULTS}

\section{Creative Stories}

Objective characteristics. Participants' creative stories in the novel object condition had a mean length of 225 words. Twenty-six percent (26.7\%) of stories in this condition were written from a firstperson point of view, and the majority were in third-person. In the familiar object condition, stories ran an average length of 470 words. Fifty-seven percent (57.1\%) were written from a first-person perspective, and third-person narration was less prevalent.

Narrative categories and subcategories. A taxonomy of four (4) narrative categories and 10 subcategories emerged from our classification of participants' stories. Figure 1 is a schematic presentation of the prevalence of each narrative category and subcategory in both conditions.

Achievement. Narratives conforming to the achievement type occurred most often in the novel object condition ( $60.0 \%$ of cases, as opposed to $28.6 \%$ in the familiar object condition). Two subcategories were identified based on differences in the conclusion. In the instrumental subtype, protagonists were rewarded for effective functioning (e.g., eating a satisfying meal after a long day on the hunt), while in the moral type, narrative completion resulted in the actualization of a moral theme in behavior. All achievement-type stories were characterized by linear, highly archetypal (Jung, 2008/1940) plot progression, from: (a) introducing the context (setting and central characters), to (b) an orienting goal, qualified by statements concerning distance between the subject and object of desire, (c) conflict or tension of opposing forces, and (d) a clear, positive outcome. Points (a)-(d) are demonstrable in the following exemplar from the familiar object condition. The participant's chosen objects are italicized: 


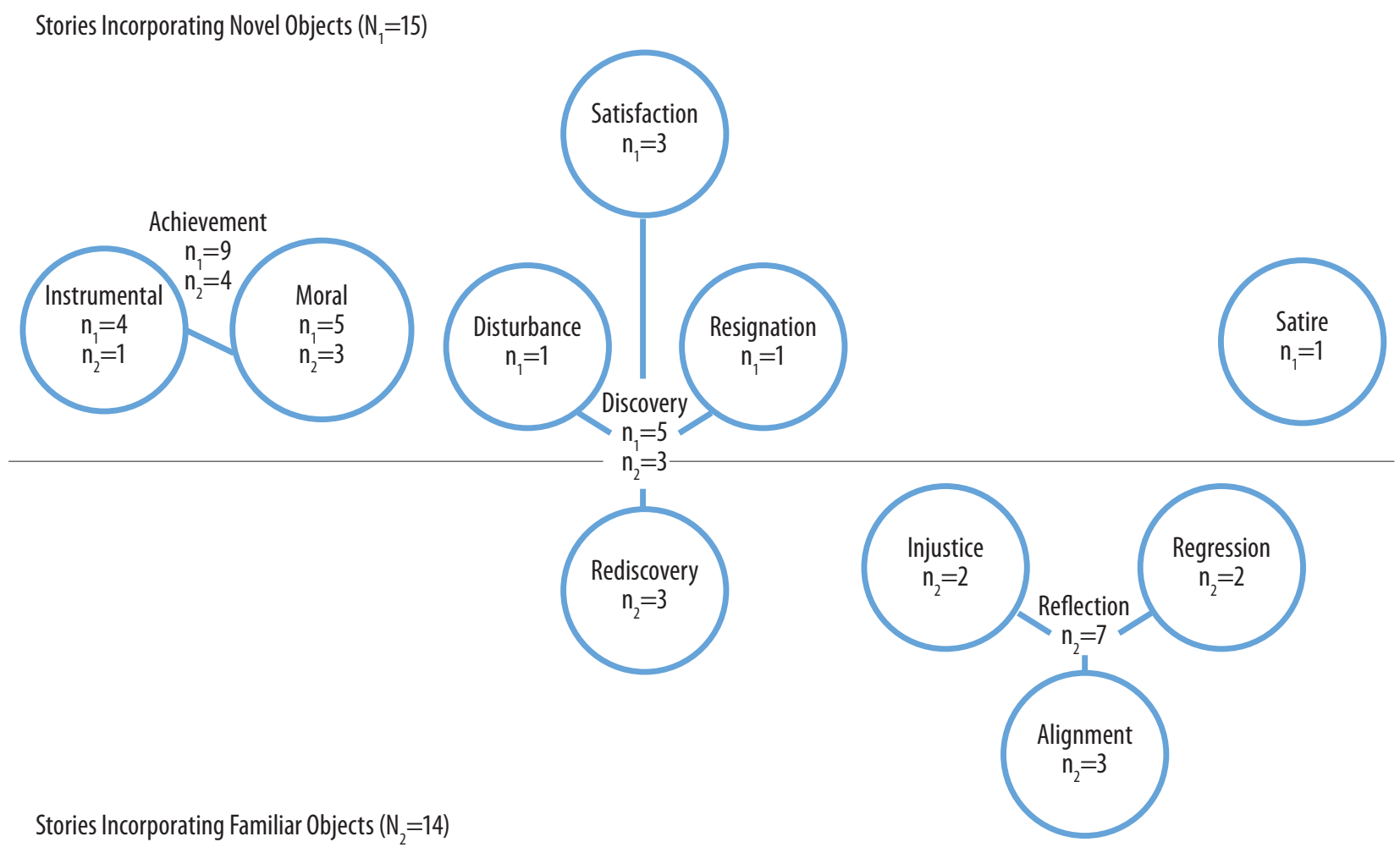

Figure 1. Map of Absolute Frequencies of Narrative Categories and Subcategories by Condition

\begin{abstract}
There was a man who traveled to a lake that was said to be able to provide insight to those who had the courage to look into its depths. When he left his town on his journey, he was given a belt of power by the village elders to help him on the way, and a pair of shoes that would quicken his pace for all of the service he had provided to the village. The way to the lake was long and arduous, but his shoes which all of his work had earned him made the trip feel short. Whenever he faced obstacles, [...] he was able to wear the belt of his elders for support. It did not lift the loads for him though-there was still much work for him to put into his journey. When he arrived at the lake, he met a stone frog guardian that told him that by confronting his fears and plunging into the depths, he would be able to emerge with something of value. Not knowing how to swim, the man jumped in anyways, and upon reaching the bottom found a watch that helped to clear his mind and help him to navigate to the surface (Male participant, age 22).
\end{abstract}

Discovery. What we refer to as discovery-type stories map onto a qualitatively different plot trajectory. Instead of a heroic journey from the known into the unknown, the locus of change or progression was from confusion to understanding - disorder to order. Often written in first-person, these narratives progressed from: (a) dream-like immersion into the subject's perspective (lack of context), to (b) an orienting goal, and (c) epiphany, or the revelation of something of value (e.g., moral) by way of exposure to the context of the story, such as a piece of history or mythology. These were termed discovery-type stories, because protagonists utilized inductive reasoning to advance from syncretic experiences to meanings. This category accounted for $21.1 \%$ of stories in the familiar object condition and $33.3 \%$ in the novel object condition.

Four subcategories were discerned on the basis of differences in the content and emotional tone of the conclusion, namely satisfaction, disturbance (horror-like), resignation and rediscovery. The 
rediscovery subcategory was unique to the familiar object condition and exemplifies the distinction between discovery- and achievement-type stories. Here, participants' objects were clues that contributed to the unearthing of a moral or deep understanding:

\begin{abstract}
I lay there. Staring at the white ceilings with the bright lights just beaming down on me. I don't know where I am. "She's awake!" someone said, and two people seemed happy to see me. Who are they? Why does my head hurt? [...] The girl told me she was my sister and the guy told me he was my boyfriend. [...] I don't remember anything. I felt so empty. I don't know who I was. [...] The next day my boyfriend and sister came back but they had boxes in their hands. They started showing me objects that apparently came from my room [...] I took them out of the box. I looked at the pair of running shoes and I smiled. I don't know why but this feeling of happiness came over me. "I used to run..." I said out loud. "Yes! YES! [...] You love to run!" my sister said excitedly. [A ring also evokes memories]. Then I picked up the tiara and it sparkled in the light. "Is this mine?" I asked them. They both nodded. My boyfriend sat on the bed and put the tiara on me. [...] He looked at me with tears forming in his eyes. I held his hand and hugged him. And then I grabbed the rosary and I immediately cried. Despite forgetting everything, I knew God and I knew who He was in my life... (Female participant, age 18).
\end{abstract}

Reflection. Half of stories in the familiar object condition were first-person reflections on situations. No stories in the novel object condition were assigned this code. In all three subcategories, protagonists experienced inner conflict and a need to discern. One case described tension between romantic and academic obligations. Another story detailed a clash of role models in which the narrator struggled between living by her father's value system or her grandfather's—stability versus spontaneity.

These narratives ended with statements related to existential themes. Three subcategories, alignment, injustice and regression, were differentiated based on the varieties of themes participants explored. Principally, reflection-type stories in the alignment subcategory $(21.1 \%$ of narratives in the familiar object condition) involved epiphanies about free will. Protagonists gained control over circumstances or progressed towards acceptance. One narrative documented the struggle towards an enduring bond with a loved one who had passed away as a result of cancer. Amid her grief, there was a revelation of acceptance:

You may have passed away, but I [felt you] passing through me [and it] was pleasant. I feel your presence, your energy, in this charm that I dedicated to you. [...] I remember God because you always reminded me to. I miss you. I hope you're well... wherever you may rest (Female participant, age 19).

Meanwhile, $14.3 \%$ of reflection-type stories, including familiar objects, were tragic narratives coded under the injustice subcategory. These were associated with a sense of powerlessness or the inability to accept. The conclusion of one participant's story captures the essence of this theme: "I should have been standing at the end of an altar, looking at him in a white gown. Not looking down into his grave" (Female participant, age 18).

The regression subcategory ( $14.3 \%$ of stories in the familiar object condition) was distinguished by ongoing unknowing. These narratives were in a sense incomplete and lacking evidence of resolution or psychic progression. As an 18-year-old female participant wrote: "I wanted to pursue a life, 
a career that was [...] what was wanted for me. But what did I really want to do? Who did I really want to be?"

Satire. The fourth narrative category accounted for only one case (in the novel object condition). Satire was defined as ironic commentary potentially organized around a socio-political theme. In our single case, a group of nonhumans (fruit) assembled to overthrow mankind in favor of an egalitarian society. The utopic government degraded into tyranny, a potential allusion to Orwell (2008/1945) and classic ironic motif.

\section{Interpretive Statements}

Objective characteristics. Participants' interpretations of their short stories had a mean length of 93 words in the novel object condition and 96 words in the familiar object condition.

Varieties of interpretations. Thematic coding of interpretive statements led us to develop a taxonomy of participants' self-reported sources of inspiration for their stories. Percentage comparisons between conditions are summarized in Figure 2.

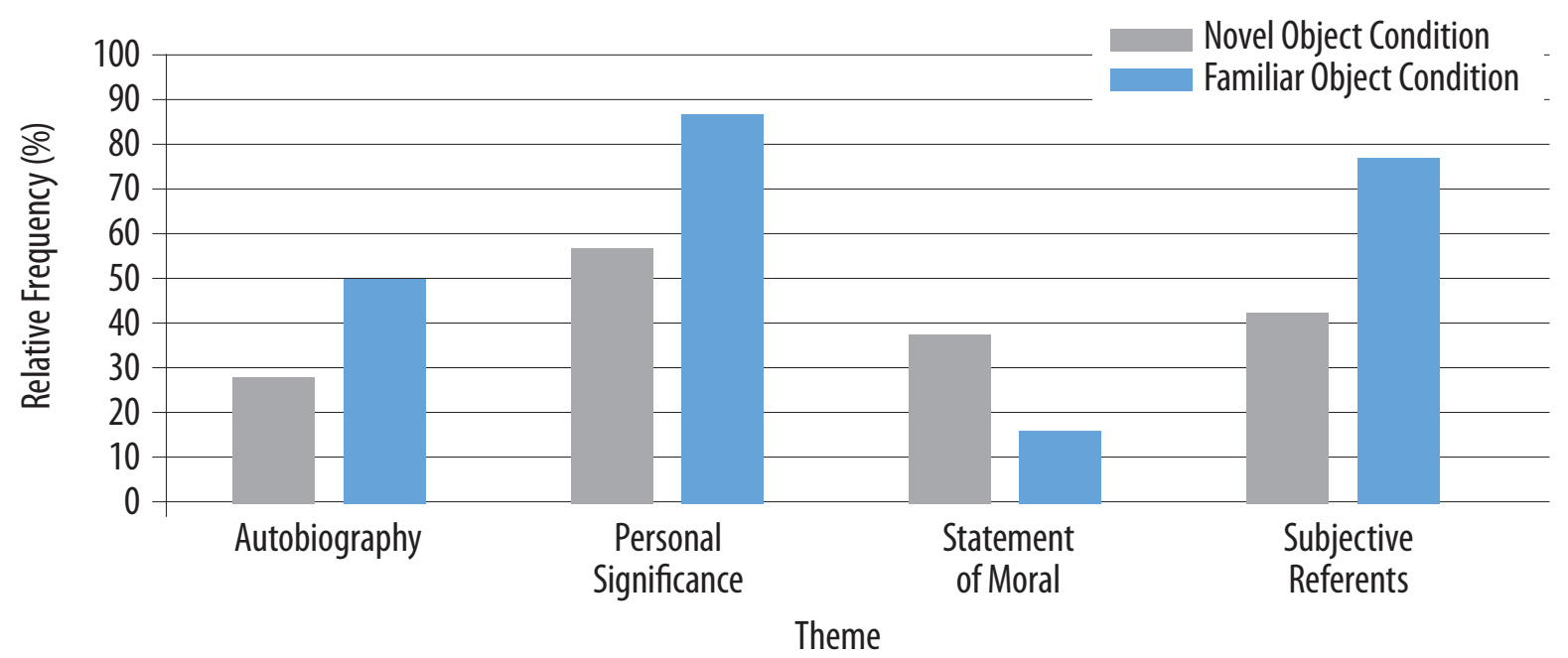

Figure 2. Prevalence of Themes in Interpretive Statements in Both Conditions

Narratives written in the familiar object condition were described as having greater personal significance to participants than stories incorporating novel objects ( $85.7 \%$ versus $57.1 \%$ of cases). "The story [with familiar objects] is related to my navigation into adult life," reported one male participant (age 22), denoting self-reflection on the theme of individuation. Furthermore, when participants looked back on their stories in the familiar object condition, they tended to write more about people or episodes in their personal life that inspired characters and plot developments (78.6\% of cases versus $42.9 \%$ in the novel object condition). Termed subjective referents, participants associated features of their stories with their parents, conflicts with romantic partners, and aspects of their personalities: 
[I am thinking about] self-destructive periods in my life. I feel guilty for allowing these feelings to branch out and affect my relationships with other people and objects (as is suggested by my damaging of the bed [in the story]). I have more difficulty knowing what to make of the birds. I suspect that the magpie represents the malignant aspects of the world I might awaken through my carelessness, or aspects of myself I have difficulty coming to terms with-as opposed to the more gentle-seeming pigeon, which initially interested me (Male participant, age 23).

In cases where subjective referents were not mentioned, especially in the novel object condition, participants often stated that they derived inspiration from objective referents. These were defined as sources of inspiration for the story that were relatively distant from their personal life narrative, including films, videogames, events in the news, or children's stories.

Statements of the moral of the story were more common in the novel object condition $(35.7 \%$ of cases) than in the familiar object condition (14.3\%). One participant described of his story: "The moral is that you should be yourself, without fear of judgment from others" (Male participant, age not disclosed).

In the familiar object condition, roughly half of participants reported that their stories were retellings of critical episodes in their lives (autobiography). This was less often the case in novel object condition stories (28.6\% of cases). Autobiographical content was often veiled in symbolic form:

The story is a representation of a love that was lost too early. For me this is meaningful because I am currently in a relationship that my mother disapproves of, and though the story is not related exactly to my personal situation, for me it is a metaphor of what I am currently experiencing as an individual is experiencing separation from my significant other at the hands of external forces (Female participant, age 18).

The reader would only be able to pick up on references to the participant's personal life by having the analogies explained to them. Participants' interpretations of symbolic autobiographies tended to be sophisticated and emotionally engaged:

\begin{abstract}
The second story [with familiar objects] means more to me than the first story [with novel objects], as it displays certain aspects of my past relationship. I find this interesting because although I could have focused on any of the four objects and their deeper meaning [...] I think, part of this may be due to the fact that my break-up has taken a toll on me and is constantly something that I think about, so despite how important other aspects of my life are to me, this very one seems to be taking precedence in this very moment. The story concludes with the character saying 'you should take risks in life,' and I find it interesting [...] as my break-up had occurred due to the fact that I didn't think I had a future with the individual I was with and was afraid of the risk. Perhaps my subconscious is speaking and regretting not taking as many risks in life (Female participant, age 19).
\end{abstract}

Most participants reflecting on autobiographical meanings described the content of their story as symbolic of actual events, and few reported that their stories were literal retellings of critical life episodes. The story "is my life," reflected an 18-year-old male participant. He continued: "I have these objects as treasured mementos. They involve episodes of my life that I can never forget, and they remind me of who I need to become and how I need to act in front of my family."

Interpretative statements of this kind were responses to reflection-type stories, often of the tragic injustice and regression subtypes. Interpretations were short. A 19-year-old female participant sim- 
ply reported that her story "was the timeline of one of my most memorable times in my life." Another participant (age 19) reflected on how the story was a meaningful outlet for "expressing [...] sadness." She situated herself in the feeling ("I'm still grieving") and wrote that she felt "confused" and unable to elaborate on the connections between her story and difficult personal experiences.

\section{Main Findings}

Creative short stories loaded with accessible, personally meaningful content through familiar objects, such as souvenirs and heirlooms, were more often written from a first-person point of view than those incorporating objects chosen from a matrix of randomly generated options. Stories in the familiar object condition also tended to be longer, and narratives commonly involved immersion into the protagonist's reflections on an existential theme. Meanwhile, stories in the novel object condition were shorter and tended to conform to archetypal structures. In interpreting their own narratives, participants tended to appraise stories written in the familiar object condition as personally significant retellings of lived experiences. Characters in these stories were frequently described as representations of aspects of the personality or parental figures. Stories in the novel object condition were not often judged to be personally significant. Rather, plot developments were reportedly inspired by popular media and literature, and participants tended to produce explicit statements of the moral of the story.

\section{DISCUSSION}

A core finding of this study was the observation that participants identified more connections between stories in the familiar object condition with meanings reflecting the personal unconscious than those in the novel object condition. In the majority of stories incorporating familiar objects, participants reported that the referents - the bases for the images appearing in their creative visions (Giegerich, 2013) - originated in their relationships to the self and close others.

Narratives classified in our study as achievement-type stories map just as well onto a Jungian hermeneutic (2008/1940) for charting plot development in sophisticated dreams. This can be summarized as follows: (a) locale, or the dramatis personae as well as temporal and physical settings, (b) exposition or problem wherein the dreamer's state of affairs is distant from an ideal, (c) peripateia, or climax and transformation, for better or worse, and (d) lysis or conclusion, often brought about by an ego-sacrificial act marking an attempt to compensate for the distance between the ideal and current state of affairs. This is an archetypal heroic arc.

Stories in the novel object condition were more likely heroic quests interpreted in light of meanings that transcend the individual (objective referents and moral statements). These stories also tended to involve pragmatic, instrumental problem-solving (Feng et al., 2017) as a driver for plot development. Conversely, stories in the familiar object condition were more often composed and/or interpreted with direct reference to personal experiences. Analytical psychology would lead 
one to postulate that archetypal ideas were inevitably present in these cases, too (Edinger, 1992). However, they would be embedded beneath rich autobiographical detail rather than as obvious scaffolding for fantastical, heroic stories. A Jungian depth-oriented conceptualization would be as follows:

1. Where collective meanings were accessible, personal meanings were embedded (prevalent in the novel object condition).

2. Where personal meanings were accessible, collective meanings were embedded (prevalent in the familiar object condition).

This hypothesis is bolstered by a third quality of interest: explicit references to the moral of the story. A moral statement is contingent on the belief that the narrative explored a theme that might resonate with other people. This means that participants in these cases reflected on their creative products as though they would a fairy tale or fable, emphasizing collective rather than personal meanings.

Another notable distinction was found between stories that their authors reflected on as symbolic retellings of lived experiences versus literal autobiographies. Sophisticated reflections referring to emotional experiences arose in symbolic-autobiographical interpretations. Meanwhile, when participants utilized the task as an opportunity to document their personal histories like a diary (frequently including painful memories), their interpretations were shorter and had limited depth. This speaks to the hypothesis that creative activity provides indirect access to difficult emotions, while a direct and unprepared encounter with the emotional charge of the experience may bring about refusal to engage (Ellenberger, 1980/1971; Slayton, D'Archer, \& Kaplan, 2011; Talwar, 2006). There were no cases in which participants interpreted literal autobiographical content in a sophisticated manner. Those who veiled their lived experiences beneath a fictionalized surface demonstrated more insights during the interpretation task, readily bridging symbol to self. Depth of reflection may reflect level insight or at least comfort with self-disclosure in the context of our study.

There were some participants who generated personal and well-developed interpretations of stories in the novel object condition. This demonstrates an ability and willingness to consciously explore how themes from personal experiences map onto fairy tale- or dream-like stories. A common position in the Zurich school is that it is worthwhile to examine (or even dialogue with) images from the imagination regardless of how distant they may appear from personal experience (Edinger, 1992). Offering support for this position is the importance of empathetic engagement in making meaning of sacred artworks (Lang et al., 2020). Recall that the heroic story may come to a close when the subject gains knowledge of some logos, elixir, profound truth or moral realization, as a consequence of an ego-sacrificial act; wounding is necessary (Campbell, 2008/1949; Edinger, 1992). The elixir signifies the individuating state, or the revelation of meaning in light of expansion of insight into previously inaccessible psychic territory (Jung, 1951). Laing (1967) defines the presacrificial ego as a "preliminary illusion, a veil, a womb state to which one has to die, from which one 
has to be born" (p. 112). Old ego boundaries are stretched or shed, and the subject gains a broader, more mature view of the Self. The subject may personally identify with these narrative features, and this was the case for some of our young adults. Participants who were able to derive insights from fantastical stories demonstrated an intuitive grasp of archetypes.

Overall, asking individuals to incorporate objects evocative of important memories may influence the creative product and interpretation.

The present study aimed to achieve a confluence of narrative and depth psychology (richness) and good practice in qualitative social science research (precision; Tobin \& Begley, 2004). Exploratory qualitative research is not intended to be generalizable, and our sample size of 15 participants (a total of 57 texts) was sufficient for both representation of individual narratives and descriptive comparisons. Statements regarding differences in the proportions of texts assigned particular codes reflect researchers' interpretations. The emergent codes and themes were based on agreement between two researchers with graduate-level training in psychology and familiarity with the relevant constructs. These were, however, the same researchers involved in the design and implementation of the paradigm. Consultation with an external auditor may have increased the trustworthiness of the study and allowed us to report more authoritative comparisons between conditions.

This study was limited to the local community of post-secondary students, and sample homogeneity is an advantage in horizontal analysis. Further study is nevertheless needed to examine the appropriateness of applying the task with different individuals and groups. Evidently, the task is contingent on literacy. Application with populations with different levels of cognitive functioning may require adaptation (e.g., an oral rather than written task).

The recommendation to triangulate or crystallize findings was not followed in the present study (Tobin \& Begley, 2004). Despite the inspiration of positivism in our design, exploration of constructive processes was prioritized in the pilot phase. A planned, larger follow-up study will include a robust pre-test questionnaire inquiring into the roles of personality and socio-cultural variables, rated appraisals of creative stories and interpretations, and reasons why participants were drawn to certain novel objects in the 36-item matrix. Qualitative findings will be considered in relationship to participants' rated appraisals of texts, raising the confirmability of the findings and granting a more complete picture of potential effects of object familiarity.

Our exploratory qualitative inquiry produced a composite description of the varieties of stories composed and subjected to their creators' reflections. In testing the novel task, we gained a sense of participants' willingness and ability to trace their projections and intuit collective and personal meanings in their stories. Manipulation of object familiarity in a task with the rationale of sand-tray therapy resulted in demonstrable differences at the levels of word length, point of view, narrative forms and features, self-disclosure and reflection. Use of familiar objects in such a task appears to be a largely untapped resource that shows promise as a route to insights about the self.

\section{Acknowledgement}

The authors would like to acknowledge the assistance of Gil Mazor Goder (Art Therapy). 


\section{References}

Bühler, K., \& Heim, G. (2001). General introduction to the psychotherapy of Pierre Janet. American Journal of Psychotherapy, 55(1), 74-91.

Campbell, J. (2008). The hero with a thousand faces. San Francisco, CA: New World Library. (Original work published 1949).

Chen, C., Kasof, J., Himsel, A., Dmitrieva, J., Dong, Q., \& Xue, G. (2011). Effects of Explicit Instruction to "Be Creative" Across Domains and Cultures. The Journal of Creative Behavior, 39(2), 89-110. https://doi. org/10.1002/j.2162-6057.2005.tb01252.x

Creswell, J.W. (2007). Qualitative inquiry and research design: Choosing among five approaches ( ${ }^{\text {nd }}$ ed.). Thousand Oaks, CA: SAGE.

Edinger, E.F. (1992). Ego and archetype. Boulder, CA: Shambhala.

Ellenberger, H.F. (1981). The discovery of the unconscious: The history and evolution of dynamic psychiatry. New York, NY: Basic Books. (Original work published 1970).

Feng, Z., Logan, S., Cupchik, G.C., Ritterfeld, U., \& Gaffin, D. (2017). A cross-cultural exploration of imagination as a process-based concept. Imagination, Cognition and Personality, 37(1), 69-94. https://doi.org/1 $0.1177 / 0276236617712006$

Giegerich, W. (2013). The flight into the unconscious: An analysis of C.G. Jung's psychology project. New Orleans, LA: Spring Journal Books.

Halpenny, E.A., \& Linzmayer, C.D. (2013). "It was fun": An evaluation of sand tray pictures, an innovative visually expressive method for researching children's experiences with nature. International Journal of Qualitative Methods, 12, 310-337.

Humphrey, K.M. (2009). Cognitive-behavioral and constructivist strategies for loss adaptation. In Counseling strategies for loss and grief (pp. 57-142). Alexandria, VA: American Counseling Association.

Ignatius of Loyola (2015). The spiritual exercises of St. Ignatius (L. J. Puhl, Trans.). New York, NY: Random House Vintage Books.

Janet, P. (1920). The major symptoms of hysteria: Lectures given in the Medical School of Harvard University. New York, NY: The Macmillan Co.

Jung, C.G. (2008). On the method of dream interpretation. In M. Meyer-Grass, \& L. Jung (Eds.). E. Falzeder, \& T. Woolfson (Trans.), Children's dreams: Notes from the seminar given in 1936-1940. Princeton, NJ: Princeton University Press. (Original work published 1940).

Jung, C.G. (1968). Man and his symbols. New York, NY: Dell. (Original work published 1964).

Jung, C.G. (1951). Aion: Researches into the phenomenology of the self. F.C. Hull (Trans.). London, UK: Routledge.

Lang, J., Stamatopoulou, D., \& Cupchik, G.C. (2020). A qualitative inquiry into the experience of sacred art among Eastern and Western Christians in Canada. Archive for the Psychology of Religion, 42(3), 317-334. https://doi.org/10.1177/0084672420933357

Laing, R.D. (1967). The politics of experience and the bird of paradise. London, UK: Penguin.

Leary, D.E. (2005). Objects, meanings, and connections in my life and career. In G. Yancy, \& S. Hadley (Eds.), Narrative identities: Psychologists engaged in self-construction (pp. 54-72). London, UK: Jessica Kingsley Publishers.

Lynn, S.J., \& Rhue, J.W. (Eds.). (1994). Dissociation: Clinical and theoretical perspectives. New York, NY: The Guilford Press.

Magnuson, S. \& Sangganjanavanich, V.F. (2011). Effective techniques: Using sand trays and miniature figures to facilitate career decision making. The Career Development Quarterly, 59, 264-273.

McNiff, S. (2004). Art heals: How creativity cures the soul. Boston, MA: Shambhala.

Moreno-Martínez, F.J., \& Montoro, P.R. (2012). An ecological alternative to Snodgrass \& Vanderwart: 360 high quality colour images with norms for seven psycholinguistic variables. PLoS One, 7(5), e37527. https:// doi.org/10.1371/journal.pone.0037527 
Neimeyer, R.A., Torres, C., \& Smith, D.C. (2011). The virtual dream: Rewriting stories of loss and grief. Death Studies, 35(7), 646-672. https://doi.org/10.1080/07481187.2011.570596

Niu, W., \& Liu, D. (2009). Enhancing creativity: A comparison between effects of an indicative instruction "to be creative" and a more elaborate heuristic instruction on Chinese student creativity. Psychology of Aesthetics, Creativity, and the Arts, 3(2), 93-98. https://doi.org/10.1037/a0013660

Orwell, G. (2008). Animal farm. London, UK: Penguin. (Original work published 1945).

Shamdasani, S. (2009). Introduction. In C.G. Jung, The red book: Liber novus, reader's edition (pp. 1-97). New York, NY: W. W. Norton.

Slayton, S.C., D'Archer, J., \& Kaplan, F. (2011). Outcome studies on the efficacy of art therapy: A review of the findings. Journal of the American Art Therapy Association, 27(3), 108-118. https://doi.org/10.1080/07421 656.2010 .10129660

Spitzer, C., Barnow, S., Freyberger, H.J., \& Grabe, H.J. (2006). Recent developments in the theory of dissociation. World Psychiatry, 5(2), 82-86.

Talwar, S. (2006). Accessing traumatic memory through art making: An art therapy trauma protocol (ATTP). The Arts in Psychotherapy, 34, 22-35. https://doi.org/10.1016/j.aip.2006.09.001

Tobin, G.A., \& Begley, C.M. (2004). Methodological rigour within a qualitative framework. Journal of Advanced Nursing, 48(4), 388-396.

Vezzoli, C. (2019). Janet and Jung: A stimulating relationship. In G. Craparo, F. Oru, \& O. van der Hart (Eds.), Rediscovering Pierre Janet: Trauma, dissociation, and a new context for psychoanalysis. London, UK: Routledge. 